\title{
Introducción \\ MUJER Y EDUCACIÓN. UN LARGO CAMINO HACIA LA IGUALDAD
}

Cuando comenzamos a trabajar en este monográfico teníamos claro que íbamos a enfocar el trabajo dando visibilidad al papel de las mujeres en el mundo. Nuestro distintos perfiles personales y profesionales supusieron un valor añadido pues nos hizo plantearnos que no debíamos circunscribir este volumen a un marco geográfico o periodo concreto de la historia de la humanidad, sino que debíamos conjugar nuestras propias perspectivas y encaminarlas a un interés superior, dando la palabra, a través de los autores y autoras, a cualquiera de las mujeres del pasado o del presente que nos desearan contar sus historias y/o experiencias.

En la actualidad sigue habiendo quienes en sus manifestaciones plantean como innecesario abordar la perspectiva de género en cualquier trabajo, incluido el académico; sin embargo, si partimos de la acertada premisa que Joan Scott da en "El género: una categoría útil para el análisis histórico", en la obra de Amelang y Nash "Historia y género" publicada por Alfons el Magnánim en 1990, en la que vincula el género a la forma histórica de construcción de la diferencia entre los sexos y que implica relaciones de poder entre ellos, nos resulta fácil extrapolar esa forma de relación en contextos del presente. Afortunadamente en nuestro país, al unísono de otros, se ha ido viendo la necesidad de evidenciar y completar los discursos con aquellos correspondientes a esa parte de la población en muchos momentos y tiempos silenciada u ocultada.

Las investigaciones y ensayos que se recogen en este número 9 de ReSed pretenden aportar su grano de arena y ofrecer cada uno de ellos un contexto de reflexión que ayude a comprender el complejo e interesado modo de relacionarse hombres y mujeres que ha obviado la participación de ellas en el desarrollo de la sociedad. Precisamente ahí es donde radica el interés de los siguientes artículos.

A lo largo de las tres secciones en la que se encuentra estructurada la revista, Ensayo, Textos y, en último lugar, Experiencias, reseñas, debates e informes, tenemos veintitrés aportaciones que van desgranando diferentes realidades femeninas a lo largo del tiempo y del espacio.

El apartado destinado a ensayos se inicia con el artículo de la profesora Consuelo Flecha García, "Soñando el futuro. Mujeres estudiantes y profesionales en Cádiz en torno a 1900", en el que se camina a través de los estudios o vida profesional de mujeres vinculadas a la ciudad de Cádiz, analizando generaciones de mujeres y resaltando el sentir de la clase media gaditana que en sus propias palabras nos expone "decididas a invertir recursos en los estudios, no solo de sus hijos, también de sus hijas, ese proceder desencadenó un viraje decisivo en el destino adjudicado a las mujeres." 
Se continúa con el trabajo de los profesores Davide Borrelli y María Luisa Stazio, de las Universidades de Suor Orsola Benincasa y Federico II, de Nápoles, en el que nos documentan sobre la desigualdad de género que persiste en las universidades italianas como resultado de políticas aplicadas en este ámbito que responden a intereses y creencias neoliberales y para ello realizan un análisis comparativo con los de la Unión Europea.

El trabajo de la profesora Guadalupe Calvo García, actual Directora de la Unidad de Igualdad de la Universidad de Cádiz, titulado "El caso de Rachida: El complicado camino hacia la igualdad de las mujeres musulmanas en la Francia de la laïcité" es un estudio sobre el sentir de mujeres musulmanas francesas a través del caso de una estudiante, de la rama de las Ciencias Sociales, en el que muestra con sus experiencias la complicada situación que vive este colectivo en el país vecino.

El siguiente artículo corresponde a los profesores Arturo Lando e Igor Scognamiglio, ambos de la Universidad Suor Orsola Benincasa de Nápoles. Analizan la labor cinematográfica del director Pedro Almodóvar desde el punto de vista de la indagación en los sentimientos femeninos y la capacidad femenina de vivir y liberar sus sentimientos en una estructura social y cultural marcada por el dominio masculino.

La profesora Lola Frutos Balibrea, de la Universidad de Murcia, con su trabajo "Feminismo y educación en los países occidentales desde la Ilustración a la actualidad. Educación, diferencia y desigualdad" nos adentra en la génesis de las desigualdades en las sociedades occidentales actuales a través de una visión crítica desde el socialismo al feminismo y a la consideración de clases.

Desde la Universidad de Talca, la profesora Leyla Torres-Bravo nos traslada al primer cuarto del siglo XX para mostrarnos cómo se ejercía la función directiva en los centros femeninos de educación latinoamericanos, qué rol ejercía las directoras y cómo incidía en la formación de las niñas y jóvenes; todo ello tomando como referencia el libro publicado en 1928, "Actividades femeninas en Chile".

Begoña Sánchez, desde la Universidad de Cádiz, en colaboración con Ana Álvarez y María Escribano nos dibujan un panorama actual resultado de las conquistas alcanzadas en pro de la igualdad, para lo que parten del desarrollo del concepto de la coeducación y su implementación real para dar respuesta al objetivo sobre "Igualdad de género" definido en los Objetivos de Desarrollo Sostenible (ODS).

La profesora de psicología de la UCA, Violeta Luque, junto a María Escalona, de la Fundación Don Bosco Salesianos, nos hacen una aproximación a los primeros resultados de grupos de trabajo de alumnas universitarias del Grado de Psicología, para seguir avanzando en las Medidas de Protección Integral contra la Violencia de Género (VG) desarrollada en la Ley $1 / 2004$.

Esta primara sección se cierra con el título "Psicopedagogas pioneras", de la profesora Ana Guil Bozal de la Universidad de Sevilla. A lo largo de sus páginas se reconstruye la vida personal y experiencia profesional de cinco mujeres adelantadas a su tiempo, precursoras en el ámbito de la Psicopedagogía y sensibilizadas con la formación femenina. Se analiza 
qué las motivó a emprender sus andanzas, sus entornos, necesidades y anhelos profesionales.

En la segunda sección, correspondiente a Textos, con diez contribuciones, se encuentra en primer lugar el trabajo Lourdes Girón Anguiozar, de la Escuela Superior de Igualdad Real H.C.C., a través del cual nos cuestiona la veracidad de la formación de la ciencia histórica, ya que al ser creada por los hombres, en masculino, este estableció para su análisis y desarrollo los principios, fundamentos y métodos encaminados a fin que perseguían: el predominio de la masculinidad sobre la feminidad.

Seguidamente, y volviéndonos a tierras italianas, bajo el prisma de la profesora Diana Salzano, de la Universidad de Salerno, nos imbuimos en el mundo Disney. La autora, a lo largo de las líneas de su trabajo, nos muestra la influencia de los medios de comunicación e indaga en la capacidad que tienen las películas destinadas a la niñez para crear historias que, aunque reflejen la realidad social, tienen la posibilidad de cambio de relación entre los géneros masculino y femenino.

A continuación Juan Luis Sánchez Villanueva, investigador perteneciente al Grupo de Investigación HUM306 Género e Historia, nos acerca al mundo de las amigas, figura femenina que a lo largo de la historia escolar española tuvo gran presencia en el cuidado y educación de los niños y las niñas, principalmente en la zona sur de España. El autor trata la labor de estas mujeres en la ciudad de Jerez de la Frontera (Cádiz), las circunstancias y condiciones en que ejercían su función.

Retomando el tema de la prevención de la violencia de género, Cecilia Palomo Caudillo, Catedrática Poder Judicial Federal de Méjico, con su trabajo "El caso de Paola Guzmán Albarracín, violencia sexual infantil en el ámbito educativo en Ecuador" pone el foco en la violencia sexual en los colegios de América Latina y el Caribe. De su mano, la autora, nos intenta hacer reflexionar sobre la necesidad de impulsar una formación dirigida a la igualdad entre hombres y mujeres a través de un caso de violencia sexual sufrida por una niña.

Seguidamente el estudio de Fátima Salaverry Baro, historiadora y experta en políticas de igualdad, nos vuelve adentrar en el siglo XIX gaditano, en este caso en la capital de la provincia. En el "Reformismo social (1838-1843): la Junta de Damas de Cádiz y la escuela de niñas pobres" nos retrotrae al Estado Liberal de España y los efectos que tuvo la Junta de Damas, de la Sociedad Económica de Cádiz, a nivel educativo, en la gestión de la escuela de la ciudad destinada a la formación de las niñas.

Otro artículo que se circunscribe al mismo siglo es el de la profesora de la Universidad de Cádiz, Cristina Rodríguez Pastor. Se analiza a Florence Nightingale, mujer que por su formación y trayectoria se considera impulsora de la profesionalización de la enfermería y defensora de la educación de la mujer, según nos manifiesta la propia autora.

A continuación, y para concluir este bloque, nos encontramos con tres trabajos de gran interés para el lector. El primero de ellos al que hacemos referencia es de Michael Steven Camelo Gómez, de la Secretaria de Educación Distrital de Colombia, y en su investigación 
etnográfica nos presenta un estudio sociocultural sobre el género en los carnavales de Cádiz. El de Santiago Sevilla-Vallejo, de la Universidad de Salamanca, nos realiza un análisis de la narrativa, imágenes y temáticas de los libros de texto de Educación Primaria, evidenciando si son o no coeducativos. El tercer trabajo al que nos referíamos, con una temática de gran actualidad, es de Enrique Lleida Lanau y Marta Sanjuán Álvarez, Universidad de Zaragoza, bajo el título "El rap y la construcción de identidad de los jóvenes raperos de Aragón", nos aproxima al análisis de la construcción de la identidad en una población juvenil que está cursando la Educación Secundaria.

La última sección del monográfico, Experiencias, reseñas, debates e informes, contiene, en primer lugar, una reseña realizada por el profesor de la Universidad de Cádiz, Eulogio García Vallinas, del libro "Educar para la paz en la globalización", de José Gerardo Chacón, editado por la Universidad de Granada. En segundo lugar, Ester Carrasquilla Hernández aporta un Plan de Investigación de tesis doctoral con el título "Estudios de Caso sobre tres modelos de parejas pedagógicas para la construcción de aulas inclusivas en Educación Infantil". Y en tercer lugar, y para cerrar, Patricia Marín del Ojo nos ofrece "La Mujer Anglosajona y su legado feminista: Guía Didáctica de Mujeres Anglosajonas en lengua inglesa para el alumnado de ESO y Bachillerato".

Para finalizar, deseamos manifestar nuestro agradecimiento a la Directora de la Revista RESED, Dra. A-Beatriz Pérez-González, por la confianza y la libertad dada a lo largo de todo el proceso de elaboración de este monográfico, así como a las revisoras y revisores científicos que sin su labor no hubiera sido posible la edición de este número.

Carmen Vázquez Domínguez Universidad de Cádiz
Manuel Domínguez Moreno

Presidente y editor de Diario16 